\title{
Trabalhonecessário
}

Issn: $1808-799 \mathrm{X}$ ano 14 ,

número $23-2016$

\section{E. P THOMPSON E EXTERMINISMO: ESTRATÉGIA PACIFISTA E LUTA}

\author{
Ricardo G. Müller ${ }^{1}$ \\ All we can do, and all that you would wish us to do, is to reason.
}

(E. P. Thompson)

Tomorrow for the young, the poets exploding like bombs,

The walks by the lake, the weeks of perfect communion;

Tomorrow the bicycle races

Through the suburbs on summer evenings.

But today the struggle.

Today the deliberate increase in the chances of death,

The conscious acceptance of guilt in the necessary murder;

Today the expending of powers

On the flat ephemeral pamphlet and the boring meeting.

Today the make shifts consolations: the shared cigarette,

The cards in the candlelit barn, and the scraping concert,

The masculine jokes; today the fumbled and

unsatisfactory embrace before hurting. The stars are

dead. The animals will not look.

We are left alone with our day, and the time is short,

And History to the defeated May say Alas

but cannot help nor pardon.

(Spain 1937, W. H. Auden)

\section{Resumo}

Percebendo a existência de "uma dinâmica interna e de uma lógica recíproca que requerem uma nova categoria de análise", E. P. Thompson elabora o conceito de exterminismo, para definir e examinar essa nova realidade, esta época histórica de confronto nuclear. Em termos teóricos, o aspecto mais controverso da interpretação de

\footnotetext{
1 Professor Associado, Depto. de Sociologia e Ciência Política e Programa de Pós-graduação em Sociologia Política (PPGSP), coordenador do Laboratório de Sociologia do Trabalho (Lastro), Universidade Federal de Santa Catarina (UFSC), Florianópolis/SC; cf.:http://ppgsp.posgrad.ufsc.br e www.lastro.ufsc.br E-mail: rgasparmuller@gmail.com
}

TrabalhoNecessário - www.uff.br/trabalhonecessario; Ano 14, Nº 23/2016. 


\section{Trabalhonecessário}

Issn: 1808 - 799X ano 14, número $23-2016$

Thompson sobre a Guerra Fria, e em relação a essa proposta, é sua abordagem do conceito de luta de classe e sua restrição às noções de imperialismo e militarismo. $O$ artigo procura discutir a importância dessas ideias e localizar sua atualidade e relevância.

Palavras-chave: Exterminismo; Realismo; Pacifismo.

\section{Abstract}

The paper analyses pieces of E. P. Thompson's political writings. The arguments point out aspects related to Thompson's practice and thought and his engagement as a pacifist, the theoretical and political debates in which Thompson was involved and some of their most important issues: his conception of socialist humanism and protest as a mode of struggle; the category of exterminism and the idea of disaster it conveyed, and his concern to build alternatives to Cold War's diplomacy and rhetoric to advocate disarmament as well. Thompson's essays on exterminism actually end up with a more optimistic view and submit an antiexterminist agenda to change the scenario and revert such risk and violent context.

Keywords: Exterminism; Realism; Pacifism.

\section{Introdução}

Recentemente o Prof. Giovanni Alves colocou uma mensagem em seu Facebook, discutindo as relações ameaçadoras entre aquecimento global, guerra nuclear e suas complexas variáveis:

\section{EXTERMINISMO}

Enquanto no começo do século XX, o dilema histórico crucial era "socialismo ou barbárie", hoje, nos primórdios do século XXI, o dilema histórico decisivo, cada vez mais candente, é "socialismo ou extermínio da humanidade". No século XX, nós perdemos. A barbárie política e social se instaurou. No século XXI, caso não consigamos derrotar o capitalismo neoliberal e a dominância das finanças; os conflitos imperiais no Oriente Médio, África e Ásia; impedir a escalada do aquecimento global e a possibilidade da guerra nuclear, assistiremos no século XXI o extermínio da humanidade tal como nós a conhecemos. (Alves, G., 10/02/2016)

A mensagem provocou vários compartilhamentos e comentários que ampliaram o debate. Trazia o sugestivo título de "exterminismo". Não havia mençãoà obra de E. P. Thompson, não era o caso e o espaço para esse tipo de referência. Mas a proposta do 


\section{Trabalhonecessário}

Issn: $1808-799 \mathrm{X}$ ano 14 , número $23-2016$

post e as questões e os argumentos colocados em um simples debate no Facebooknos fazem pensar mais uma vez na importância e atualidade das obras de Thompson sobre a categoriaexterminismo, os problemas supostos em seu campo de análise e as leituras e atualizações possíveis, por exemplo.

Tendo em vista a oportunidade aberta pelos conteúdos desse debate, revisamos nesse texto alguns aspectos de nossos estudos sobre o tema. Com esse objetivo, retomamos algumas hipóteses de Peter Linebaugh (1993)sobre a obra de E. P. Thompson como ponto de partida. ${ }^{2}$

Em seu artigo - uma homenagem a E. P. Thompson, no ano de sua morte, e uma avaliação crítica de sua obra - Peter Linebaugh (1993, p. 90-91) estabelece algumas hipóteses bem instigantes e de interesse para nossa pesquisa. ${ }^{3}$ Antes de resumi-las, observamos que a exposição de Linebaugh (1993, p. 89) está orientada pelo princípio da razão, pela insistência no raciocínio crítico, na argumentação cuidadosa e lúcida, tal como Thompson sempre propôs e defendeu - enfim, a relação entre reason e reasoning, temas sempre presentes em seus ensaios, especialmente em The PovertyofTheory(1978). ${ }^{4}$

Em sua argumentação, Linebaugh propõe que a obra de Thompson seja considerada de forma integrada, bem como reconhecida a unidade de seu perfil intelectual e político. Nesse sentido, a separação apresentada - entre sua obra deHistória e de Política -, é basicamente analítica e didática e objetiva facilitar a discussão das questões contidas nas hipóteses, estabelecer as correlações entre elas e uma base comum para a problemática estudada. Acompanhando o tom usual de ironia

\footnotetext{
2 Utilizamos prioritariamente, para consulta e referência, livros e artigos no original em inglês. Sempre que possível, citamos as traduções publicadas e/ou indicamos as edições disponíveis em português.

${ }^{3}$ Projeto $A$ atualidade da categoria exterminismo em E. P. Thompson, com o apoio de bolsa PIBIC.

${ }^{4} \mathrm{~A}$ problemática da razão é um tema recorrente na obra de Thompson e fundamental para seu entendimento. A motivação básica de Thompson em escrever A Miséria da Teoria foi o resgate da razão, a seu ver, ameaçada teórica e politicamente pelo estruturalismo, pela obra de L. Althusser e seguidores, e pela correlata crise no interior do marxismo. No "Prefácio", na primeira parte de A Miséria..., e em sua "Carta Aberta a Kolakowski", percebemos a dimensão de sua angústia quanto ao problema. Cf. Thompson, E. P. (1978, p.: i-v; 131; 193-194).
}

TrabalhoNecessário - www.uff.br/trabalhonecessario; Ano 14, No 23/2016. 


\section{Trabalhonecessário}

Issn: 1808 - 799X ano 14, número $23-2016$

do estilo de Thompson, e destacando sua atitude de compromisso e envolvimento, Linebaugh(1993, p. 89) observa que, depois da Segunda Guerra, Thompson tornou-se um historiador e escreveu livros de História; mais tarde tornou-se um pacifista (peaceworker, no original), e entãotambém escreveu sobre o tema.

Como mencionado, segundo Linebaugh (1993, p.. 89-90), a obra de Thompson pode ser dividida entre escritos históricos e políticos. Mas é uma divisão formal. Inclusive artificial, porque exclui, por exemplo, sua poesia e seu livro de ficção (The SykaosPapers, 1988) e, ao mesmo tempo, impede a compreensão das relações existentes entre eles ea da sensibilidade estética e artística de Thompson sempre presente em suas produções.

Não obstante, é uma distinção que ele mesmo propôs. Em The PovertyofTheory (1978), Thompson definiu a História como o seu campo de trabalho preferido. ${ }^{5}$ No Prefácio de Costumes em Comum, ele afirma que "no princípio da década de 1980 a emergência da 'Segunda Guerra Fria' e as pesadas demandas do movimento pacifista me desviaram de novo deste trabalho"(o de historiador) (Thompson, 1998, p. 9).

Nesse sentido, Linebaugh (1993, p. 90) propõe uma hipótese com um ângulo interessante de abordagem sobre a obra de Thompson. O ponto de partida para essa reflexão, ou a base comum para a problemática que ele quer discutir, está na presença do tema da morte violenta e suas variantes. Linebaugh (1993, p. 90) percebe que nos livros de História de Thompson a morte violenta é caracterizada pelo enforcamento, não pela guerra, enquanto em seus livros e estudos considerados políticos, a morte violenta é representada pela guerra, não pelo enforcamento.

Linebaugh (1993, p. 90) admite que a proposição deva ser avaliada e que contém alguns pressupostos que precisam ser discutidos - tais como que os escritos prioritariamente políticos de Thompson estão preocupados sobretudo com a guerra, e a maioria de seus livros de História (e/ou de historiografia) estão preferencialmente

\footnotetext{
${ }^{5}$ Tradução brasileira, A Miséria da Teoria, Rio de Janeiro: Zahar, 1981. Só foi publicado esse texto; não foram incluídos os outros ensaios da edição original inglesa de 1978.
}

TrabalhoNecessário - www.uff.br/trabalhonecessario; Ano 14, No 23/2016. 


\section{Trabalhonecessário}

Issn: 1808 - 799X ano 14, número $23-2016$

voltados para o problema do enforcamento ou da pena capital, não se referindo diretamente ao tema da guerra, a não ser como um fenômeno externo ou eventual.

A partir dessas observações, podemos concluir uma nova hipótese relevante para nossa investigação: como os estudos políticos de Thompson estão preocupados com a guerra - em particular, com a articulação entre os temas da Guerra Fria e da guerra nuclear -, é coerente que ele tenha procurado se envolver intelectual e politicamente com a questão, e mobilizar grupos e movimentos pacifistas para enfrentar o problema. Parece uma formulação simples, mas deve ser analisada e discutida.

Assim, com base nas considerações anteriores, retomamos os argumentos e questões que interessam ao foco central do artigo, que pretende estabelecer a relação dialética entre a definição da categoria exterminismo proposta por E. P. Thompson e sua ação intelectual e política anti-exterminista e pacifista junto aos grupos e movimentos que liderou ou de que participou.

\section{O legado de E.P. Thompson}

A contribuição de E.P. Thompson é única se consideramos um conceito de teoria política que relacione filosofia, historia e compromisso político. Ela é observada em diferentes áreas acadêmicas e campos temáticos, como os estudos de movimentos sociais, que exigem rupturas de fronteiras e mediações mais sistemáticas.

Os estudos de E. P. Thompson valorizam a importância da praxis abarcando as práticas, experiências, aspirações e os valores comunitários da classe trabalhadora e formando objetivos e aspirações para os submetidos a circunstâncias políticas adversas, que precisam elaborar e defender sua própria opinião política.Ao mesmo tempo, um dos princípios metodológicos básicos de sua análise reside em sua exigência - e habilidade - de articular a teoria à pesquisa empírica, destacando a historicidade das categorias. 


\section{Trabalhonecessário}

Issn: 1808 - 799X ano 14, número $23-2016$

Para Thompson, o dissenso, os movimentos de oposição podem conquistar direitos efetivos para a classe trabalhadora. Tal noção implicou, em primeiro lugar, um enfrentamento com as correntes comunistas que não admitiam nenhuma perspectiva de mudança na ortodoxia estabelecida. Em segundo, articulados à noção de dissenso, a metodologia e as categorias propostas por Thompson questionam as abordagens ortodoxas de investigação das relações sociais.

Além de seu trabalho teórico e historiográfico, o autor também desenvolveu uma intensa atividade política orientada por sua concepção de socialismo e pela defesa de suas ideias. Sua presença nos movimentos pacifistas - e na organização de documentos, ensaios e livros - revelou até que ponto seu ideal de marxismo estabeleceu um núcleo de convergência de uma tradição crítica e de praxis radicais. Seu ativismo político e as polêmicas em que esteve envolvido, associados à importância atribuída aos temas relacionados à luta dos trabalhadores e sua contribuição intelectual para a elaboração de uma "história vista de baixo", permitem que Thompson seja um dos historiadores e intelectuais socialistas ingleses mais eloquentes e influentes.

Sua interpretação do materialismo histórico se distingue por articular de forma construtiva as aspirações políticas e o processo histórico. O princípio dessa abordagem é que toda análise teórica deve ser apreendida na prática da ação humana (agency) $e$ pelo diálogo crítico entre teoria e prova (evidência), i.e., a teoria e a investigação empírica, e sem abandonar a atuação política. A análise dos sujeitosenvolvidos na construção de seu próprio destino passou a ser o foco principal dos estudos de Thompson, definindo uma relação de compromisso entre sua própria atuação e o que acreditava constituir um movimento social democrático. A partir desse compromisso, entende que política, história e teoria socialistas devem participar integralmente desse processo de democratização.

\section{Liberdade política e desarmamento nuclear}




\section{Trabalhonecessário}

Issn: 1808 - 799X ano 14, número $23-2016$

O ativismo político de Thompson prioriza a crítica a dois dos problemas mais cruciais que a classe trabalhadora enfrentou nos últimos anos do século $X X$ - a violação sistemática das liberdades civis e políticas e a proliferação dos armamentos nucleares. Unindo teoria e prática, Thompson concentrou seu trabalho em uma série de questões e experiências que, por mais de quarenta anos, expressaram uma significativa consistência e atitude intelectual coerente. Fiel às premissas dos "eventos de 1956", ${ }^{6}$ assume como seus o papel e o compromisso de reafirmar os princípios socialistas lutando contra 0 autoritarismo e políticas estatistas. ${ }^{7}$ Nesse contexto, articulou una proposta de uma política vista de baixo, considerando seu projeto crítico de uma história vista de baixo. A construção e a defesa do pacifismo nuclear, aliadas a uma tradição de política libertária, tornaram-se o principal tema da atividade política de Thompson a partir dos anos de 1980.

O ponto central dessa dinâmica é a união mediante a luta, capaz de articular os interesses organizados ao longo do processo histórico, buscando superar conflitos e contradições. Thompson considera que nas condições contemporâneas (sobretudo no início dos anos de 1980), as reivindicações pelas liberdades civis poderiam ser um catalizador para os movimentos populares e consolidar um cenário mais amplo e nítido para a luta de classe.

Assim, a luta do autor pelos direitos civis pode ser demarcada por sua oposição a quatro ações políticas básicas: o apelo do governo à ideia de "interesse pela Nação", que outorgaria legitimidade para aprovar qualquer iniciativa do Estado; a intervenção do Estado no sistema legal; a administração e a manipulação da mídia e a crescente tendência orientada para um estado de segurança, em que as vozes da oposição são submetidas a dispositivos de constante vigilância, censura e repressão.

\footnotetext{
${ }^{6}$ Os principais acontecimentos de 1956 têm um importante significado político para Thompson e para sua motivação em defender essa memória e tradição de compromissos. Entre eles, estão: o relatório de Kruschev, em uma Assembleia do Partido Comunista da União Soviética (PCUS), sobre os crimes da era Stalin; a invasão daHungria (Budapeste) pelas tropas soviéticas; os incidentes (entre Inglaterra, França, Rússia, Estados Unidos e a ONU) envolvendo o controle do Canal de Suez e a tentativa de derrubar Nasser do governo do Egito.
}

7 Cf. Thompson, E. P. (1991), “Endsand Histories”, in Kaldor, M. (ed.), 1991, p. 7-25.

TrabalhoNecessário - www.uff.br/trabalhonecessario; Ano 14, No 23/2016. 


\section{Trabalhonecessário}

Issn: 1808 - 799X ano 14, número $23-2016$

A defesa de Thompson das políticas de libertação também incorpora sua preocupação com a questão da luta de classe, sem dúvida um dos eixos de sua obra. Suas primeiras colocações sobre esta máxima socialista e o papel da ideologia na manipulação da consciência de classe, aparecem em seu artigo de 1960,

"OutsidetheWhale" - "Fora da baleia", parafraseando o ensaio de George Orwell, "InsidetheWhale". ${ }^{8}$ A surpreendente apatia popular frente a possibilidades catastróficas era o que mais the incomodava.

Para Thompson, esta situação resulta da política de consenso popular implementada em torno da polaridade da Guerra Fria desde 1945. Criaram-se visões ortodoxas e ideologias a fim de desenvolver uma consciência para confirmar esta polaridade. $\mathrm{Na}$ União Soviética, a ideologia fora efetivamente definida como antiimperialismo.

Em "Natopolis" se forjou uma ortodoxia mais flexível, pragmática, e por isso mais difícil de ser definida. ${ }^{8}$ Esta aparente flexibilidade provavelmente era sustentada por uma falácia: a ilusão de que não haveria nenhuma ortodoxia e que a liberdade de expressão para todos era o sistema que prevalecia. Por essa razão, os autocratas de Washington poderiam falar de um "mundo livre".

Thompson (1978, p. 3) considera que o locus da força da ideologia "natopolitana" reside na manipulação da consciência popular. O resultado da manipulação desse consenso foi uma apatia geral que operou a favor dos interesses das ideologias dominantes e os "centros de ação" foram aprisionados. Thompson (1978, p. 3-4) crê que essa tendência hegemônica seria um produto de sua própria lógica, mais que o de um ambiente deliberado de conspiração.

\footnotetext{
${ }^{8}$ Cf. Thompson, E. P. (1978, p. 1-34). Cf.: Thompson, E. P. et al (ed). Out ofApathy, Londres: Stevens \& Sons/New Left Books, 1960. Cf. nota in Thompson, E. P. (1978, p. 399). Publicado em 1940, um dos temas do ensaio original de George Orwell é uma crítica ao livro de Henry Miller, Trópico de Câncer. "Natopolis" ou Ocidente, sarcástico termo de Thompson - uma ironia com relação ao poder exercido pela NATO (North AtlanticTreatOrganization)/OTAN (Organização do Tratado do Atlântico Norte). Com a mesma ironia, Thompson se refere a "natopolitano(a)" e "natopolitanismo".
}

TrabalhoNecessário - www.uff.br/trabalhonecessario; Ano 14, Nº 23/2016. 


\section{Trabalhonecessário}

Issn: 1808 - 799X ano 14, número $23-2016$

Segundo ele, a hegemonia ocidental construiu, em sua base ideológica, um violento determinismo moral, como um espelho do estalinismo soviético, uma identificação disfarçada para fomentar uma fictícia e maniqueísta luta do bem contra o mal em nome da humanidade. No Ocidente, o sistema promoveu um estado de defesa contra o comunismo. Essa argumentação criou a imagem de um inimigo sempre presente - um gigante científico, a sociedade soviética, bem sucedida, mas fortemente predadora (Thompson, 1978, p. 11). A ameaça tinha uma direção precisa: o comunismo revolucionário, uma força que então avançava - aparentemente de maneira triunfante sobre Cuba, o Leste Europeu e os países em desenvolvimento.

Na visão de Thompson (1978, p. 11-12), era necessária uma economia de guerra permanente enquanto a cultura "natopolitana" era maquiada para ocupar um vazio e justificar o status quo.Oconstructo ideológico chegava quase a um fundamentalismo em sua "cruzada contra o mal" e, em uma espiral de dependência ideológica, o estalinismo (ou "a ideia satânica") era a justificação funcional para o "natopolitanismo". A ideologia "natopolitana" foi cuidadosamente incentivada (sobretudo pelo governo inglês). Promoveu-se um desencanto niilista, a crença de que as pessoas seriam impotentes para atuar no processo histórico e influir sobre possíveis mudanças. Sob essa coerção, muitos sacrificaram seu poder de ação.

Thompson e seus companheiros da primeira geração do movimento new left ("nova esquerda") - como Raphael Samuel, Peter Worsley e Kenneth Alexander denunciam que esse controle hegemônico da sociedade ocidental era, em verdade, uma preparação para a guerra. Não obstante, Thompson permanece otimista, acreditando que a partir do pessimismo reinante e das divisões surgidas da Guerra Fria poderia prevalecer uma verdade humana e radical.Segundo Thompson e seus companheiros, essa verdade se expressava na (então) Europa Oriental pelos "eventos de 1956" e no Ocidente pela negação da ideologia "natopolitana" presente na ação dos movimentos pacifistas e na Campanha pelo Desarmamento Nuclear (Campaign for 


\section{Trabalhonecessário}

Issn: 1808 - 799X ano 14, número $23-2016$

Nuclear Disarmament/CND). ${ }^{9} \mathrm{O}$ autor reconhecia nesse movimento um "humanismo rebelde", contra a corrente dos problemas causados pela situação de passividade, do crescente aumento dos mecanismos de controle estatal e da proliferação dos armamentos nucleares. ${ }^{10}$

De acordo com Thompson (1980, p. 1-10), o contexto de maior fechamento político (a administração do Partido Conservador inglês na década de 1980, sobretudo o período de Margareth Thatcher, e a primeira metade dos anos de 1990), as perspectivas menos ortodoxas eram recebidas com cautela pelo establishment, em particular as que divulgavam ou discutiam as ideias políticas novas ou radicais. A união entre o governo e o poder dos meios de comunicação foi capaz de bloquear sistematicamente a implementação de tendências mais progressistas.

Como ocorreu com a CND-que no início dos anos de 1960 ganhou o apoio de amplos setores da sociedade -, a heresia de ser não ortodoxo impediu que este movimento alcançasse um público maior, perdendo espaço e apoio, incluído entre os temas e matérias proibidos pela direção da mídia britânica. Na mídia, o desacordo não podia aparecer como uma perspectiva coerente, competente, confiável ou legítima.

O governo Thatcher, a partir de 1979, iniciou uma progressiva restrição ou redução de direitos civis e liberdades, em especial as conquistadas pela classe trabalhadora em muitas décadas de luta (Thompson, 1980, p. ix-x). A erosão dos direitos adquiridos, tanto pela administração do ConservativeParty,como a do LabourParty, envolveu a sociedade britânica em um núcleo reacionário. Para Thompson (1980, p. ix), a mídia teve uma forte influência nesse fechamento, estabelecendo o consenso e criando uma situação de

\footnotetext{
${ }^{9}$ Campaign for Nuclear Disarmament (CND), fundada em 1958. Sua página na internet (www.cnduk.org) revela que o grupo continua ativo, promovendo debates e manifestações, e integrado às redes sociais.

10 Para mais informações sobre a situação da Inglaterra,na segunda metade dos anos de 1950, nos conflitos do Canal de Suez, a invasão russa sobre a Hungria e Budapest, a criação da CND, o debate sobre a questão nuclear e a instalação de mísseis dos Estados Unidos em território inglês, o colonialismo e o racismo na Inglaterra, os conflitos políticos do país, o papel da mídia na cobertura desses eventos e temas durante o período da Guerra Fria, ver a série The Hour, cujos personagens principais compõem uma equipe de um programa (fictício) de reportagem e debate político na BBC da época. Ficção à parte, é possível recuperar dados e imagens desses acontecimentos. Suas temporadas

(2011/2012) foram exibidas no Brasil pelo canal Globosat em 2015.
}

Cf. www.imdb.com/title/tt1778108/?ref =nv sr 2

TrabalhoNecessário - www.uff.br/trabalhonecessario; Ano 14, No 23/2016. 


\section{Trabalhonecessário}

Issn: 1808 - 799X ano 14, número $23-2016$

apatia e submissão, o que facilitou o ataque do governo aos direitos e meios de subsistência das pessoas que, ironicamente, haviam elegido esse governo como seu representante. Para Thompson (1980, p. x), o profundo servilismo britânico à OTAN é um bom exemplo das condições da época.

Em "The StateoftheNation", Thompson (1980, p. xi) revela a gravidade do controle do Estado e apela por maior envolvimento e unidade da população contra essa tendência autoritária. Dirige-se a um público amplo (todos os democratas, não apenas "a esquerda"). Ele leva em conta que desde 1968 os potenciais grupos oposicionistas ingleses haviam se fragmentado, tornando-se sectários, organizando-se por segmentos sociais (homossexuais, mulheres, etnias,...), grupos e movimentos pacifistas e, portanto, lançando campanhas e movimentos dirigidos, com temáticas específicas (contra a Guerra Fria, a ameaça nuclear, pela paz, pelos direitos de gênero, etc.).

Nesse contexto, formavam-se também o que Thompson denominou "culturas alternativas de esquerda", e ele considerava que essa base sectária, sobre a qual esse processo se desenvolvia, poderia reduzir os potenciais de união, coerência ou resistência, na medida em que dispersava os recursos - materiais, emocionais, logísticos - em uma variedade de assuntos e campanhas. Thompson propõe que os movimentos e grupos alternativos promovam uma resistência coletiva para agir em um teatro nacional de conflito. Essa estratégia significa que "cada um dos grupos da esquerda deva ter para consigo as responsabilidades dos outros grupos, sem perder nenhum de seus princípios": 11

A noção primordial que tem circulado é a de que cor, gênero ou preferências devem ser sempre, em qualquer circunstância, os principais fatos existenciais, os que têm sempre primazia e que essas diferenças constituem barreiras quase insuperáveis, inibindo a ação política comum em uma centena de outros tipos de situações. [Essa noção] pode ter premissas válidas como ponto de partida. Mas quando pressionada em demasia [levada ao limite], e quando, coletivamente,os que estão sob a

\footnotetext{
${ }^{11}$ Cf. Bess, M. (1993, p. 124).Em correspondência com Michael Bess, Thompson observou que os marxistas precisavam incorporar todas as perspectivas em uma ética única de democracia, e que "o marxismo sempre subestimou religião, nacionalismo e formações de gênero".
} 
Issn: 1808 - 799X ano 14, número $23-2016$

ameaça de uma guerra nuclear ou da perda de seus direitos e de seu trabalho, ou estão sob uma exploração econômica comum, [essas pessoas] não podem mais efetivamente trabalhar juntas, uma vez que nutrem essas diferenças primárias com ressentimentos, o que pode vir a ser um perigoso divisor. E indicar, ademais, o fim de importantes [...] tradições de políticas radicais e socialistas dos trabalhadores. (Thompson, 1980, p. xi-xii).

Diante de uma manipulação política tão bem sustentada e difundida em toda a mídia tornava-se indispensável articular uma agenda democrática e encontrar formas mais criativas de atingir o público. Ao lado de Stuart Hall e Raymond Williams (e outros como Tony Benn e Michael Foot), Thompson (1980, p. xiii) reclama a reconstrução de um front popular efetivo e vigoroso, reminiscência do movimento dos anos de 1930, que ele tanto admirou. ${ }^{12}$

\section{Enfrentando o status quo da Guerra Fria}

As iniciativas do Governo Thatcher de implementar o monetarismo, associadas à efetivação de uma política neoliberal, ao mesmo tempo em que eram adotadas medidas agressivas com vistas a administrar a crise com a Argentina e a guerra das (Ilhas) Malvinas, certamente justificam o tom pessimista de Thompson. Esse pessimismo se manifestou em um artigo publicado em The Times (29 de abril de 1982),

"The War ofThatcher's Face", três semanas após o início do confronto (2 de abril). No artigo, Thompson (1982b, p. 191) descreve a natureza hipócrita da política da Guerra Fria, que possibilitava, e até mesmo incentivava países do Ocidente a manter um relacionamento positivo com a ditadura argentina e a lhe vender armas, sem nenhum

\footnotetext{
${ }^{12}$ Referência à Frente Popular internacional, e os movimentos de apoio e solidariedade que se organizaram durante a Guerra Civil Espanhola.
}

TrabalhoNecessário - www.uff.br/trabalhonecessario; Ano 14, Nº 23/2016. 


\section{Trabalhonecessário}

Issn: $1808-799 X$ ano 14 , número $23-2016$

constrangimento moral ou político:13 "O mundo avançado não pode seguir despejando armamentos no Terceiro Mundo e esperar que tudo continue igual. Não podemos ter certeza de que essas armas serão usadas somente para matar seu próprio povo ou [...] reprimir seus pobres[...] e não contra os inimigos de Sua Majestade". Thompson percebeu a "guerra das Malvinas" como uma das mais significativas consequências desse comércio de armas. ${ }^{14}$

Todavia, como parte dessa estratégia, segundo ele, a imprensa britânica desenvolvia um tipo de "doutrinação subliminar" que conduzia a um consenso sobre o tema dos mísseis, levando a população a pensar que as medidas haviam sido efetivamente formuladas e decididas no país. Mas, na verdade, mesmo apoiadas por um consenso nacional, não foram sequer discutidas no parlamento.

Por exemplo, a BBC não autorizou que Thompson participasse, em 1981, de um programa especial (DimblebyLecture) sobre os movimentos pela paz e a campanha antinuclear, coordenado por Jonathan Dimbleby, jornalista político. $O$ texto elaborado por Thompson para esse programa deu origem ao documento BeyondtheCold War, editado em 1982.

Thompson denuncia que, ao divulgar a informação, o sistema - governo, mídia, etc. - convencia a opinião pública de que determinados temas eram de interesse nacional. Tendo o domínio da informação, o sistema pode controlar o questionamento que se realiza. Apesar desse controle, Thompson (1980, p. 263) observa que outras vozes mobilizaram setores da sociedade, como ocorreu com o apoio à CND e a Marcha a Aldermaston. ${ }^{15}$

\footnotetext{
${ }^{13}$ O termo "autoritária" era o mais usado pela mídia, depois substituído por "totalitária". Nessa inflexão, não convém esquecer a invasão do Timor Leste, pela Indonésia, em 1975, incentivada pelos Estados Unidos, e subseqüente genocídio praticado com armas de fabricação inglesa.

${ }^{14}$ No caso, o fomento sistemático de golpes de Estado nas Américas Central e do Sul (sobretudo de caráter militar), em especial por parte dos Estados Unidos, durante as décadas de 1960 e 1970, e a posterior sustentação dos regimes advindos desses golpes, processo do qual a Inglaterra também participou. Por esse motivo, sua forte defesa do internacionalismo e do diálogo internacionalista (Thompson, 1978, p. iv).

${ }^{15} \mathrm{Em}$ Aldermaston, Berkshire, localiza-se uma Atomic Weapons Establishment (AWE), uma planta onde, desde 1950, são realizadas pesquisas e desenvolvidos artefatos nucleares. As manifestações populares
}

TrabalhoNecessário - www.uff.br/trabalhonecessario; Ano 14, No 23/2016. 


\section{Trabalhonecessário}

Issn: 1808 - 799X ano 14, número $23-2016$

No contexto da Guerra Fria, a Grã-Bretanha havia assumido o papel de base avançada da OTAN. ${ }^{16}$ Frente a um eventual ataque da então União Soviética, o objetivo era diversificar os alvos, de modo a evitar um ataque concentrado nos Estados Unidos. Nesse cenário, o povo britânico (como o russo) seria a principal vítima do conflito. Segundo Thompson (1980, p. 267), a subserviência aos Estados Unidos constituía a principal contribuição britânica à OTAN e os que se opunham a essa posição eram consideradosrebeldes e opositores do consenso. A retórica da Guerra Fria retoma, naquele momento, a tônica da perseguição ao inimigo interno.A resposta de Thompson a esse controle sistemático reitera suas posições e a de seus companheiros desde os primeiros dias da CND, quando ainda acreditavam que uma razão democrática e popular pudesse prevalecer.

Segundo Thompson (1980, p. 272), as linhas básicas da política de neutralidade ativa, advogadas desde os primeiros momentos da new left, foram discutidas nos conselhos da CND e novamente defendidas no "Manifesto de $1^{\circ}$ de Maio" (May Day Manifesto), em 1968, edição coordenada por Raymond Williams.

Em artigos do final de 1979, Thompson (1980, p. 273-274) apresenta cinco hipótesespara sustentar essas linhas básicas.A primeira hipótese é a da instabilidade do status quo nuclear e a da probabilidade de que fosse desencadeada uma guerra nuclear global; a segunda, a de que esse status quo é um "estado degenerativo", na medida em que supõe políticas "confidenciais", burocráticas e autoritárias; a terceira, que essa condição havia desenvolvido interesses militares, industriais e econômicos - com fortes

\footnotetext{
da CND contra a instalação de armas norte-americanas em Aldermaston ganharam destaque em 1961, com passeatas em Londres e Glasgow durante a transferência de um submarino nuclear dos EUA, carregado de 16 mísseis atômicos Polaris, para HolyLoch, Escócia. A principal marcha ocorreu em 31 de março, partindo de Aldermaston e Wethersfield, estendendo-se até 3 de abril, quando o protesto encerrou com o cerco à embaixada norte-americana em Londres. Como desfecho da marcha, a polícia dissipou os manifestantes sob coerção física, prendendo 31 pessoas. Na ocasião, Bertrand Russell, um dos organizadores do movimento, expressou um de seus objetivos afirmando que "nós permanecemos juntos a favor da sanidade em um mundo que enlouqueceu". Cinco meses depois, durante uma manifestação em Trafalgar Square (Londres), Russell (de 89 anos) e sua esposa seriam detidos e condenados a uma semana de prisão - cerca de 1.000 participantes também foram presos e condenados a penas maiores por se recusarem a "manter a paz" (sic).

${ }^{16}$ Cf. Thompson, E. P. (1980, p. 267), citando artigo de Sir James Goldsmith, Now!, 9-15 de novembro de 1979.
}

TrabalhoNecessário - www.uff.br/trabalhonecessario; Ano 14, No 23/2016. 


\section{Trabalhonecessário}

Issn: 1808 - 799X ano 14, número $23-2016$

características cartelizadas ou monopólicas - que deveriam ser mantidos. Nesse contexto, os dois países líderes dessa polaridade (Estados Unidos e União Soviética), embora em campos opostos, tendiam a constituir um interesse comum, marcadamente antidemocrático e não hesitavam em reprimir eventuais iniciativas de oposição.

A quarta hipótese afirma que uma détente (distensão) não iria emergir "de cima”, uma vez que, como Thompson assinala, "o estado de permanente terror favorece a conquista de poder interna e externamente a essas elites". Finalmente, a quinta indica que o caminho mais viável para a desarticulação do sistema só poderia ser um ataque a partir de baixo. Thompson acredita na importância de uma iniciativa popular baseada na neutralidade ativa, juntamente com outros movimentos antinucleares, para encorajar a dissidência através da Europa. ${ }^{17}$

Coerente com sua defesa do humanismo, Thompson (1980, p. 275) observa: "Nós já estamos em risco - Grã-Bretanha, Europa, civilização, o projeto humano [...]".Essealerta indica a convicção de Thompson sobre a necessidade de maior apoio para um novo grupo, oEuropean Nuclear Disarmament (END) ${ }^{18}$-um movimento paneuropeu destinado a combater os interesses políticos e militares de soviéticos e norteamericanos na Europa, idealizado por Ken Coates, também ativista da Bertrand Russell Peace Foundation. ${ }^{19}$

Na perspectiva de Thompson (1982, p. 10-11), o conflito dependia do antagonismo e da retórica dos irreconciliáveis sistemas militares e industriais dos dois blocos:"Cada umdeve ser motivado, em sua natureza inerente, pelo desejo de vencer o outro. Só o

17 Cf. Thompson, E. P.: (1980, p. 277-282) "European Nuclear Disarmament", originalmente em The Guardian, 28 de janeiro de 1980; (1982b, p. 109-112), "A Show for theEuropeanTheatre", originalmente em The Guardian, 23 de fevereiro de 1981; (1982b, p. 119-122), discurso no Hyde Park, Londres, 24 de outubro de 1981.

${ }_{18}$ (Apelo ao/ou Campanha pelo) Desarmamento Nuclear Europeu (END). A partir daqui citado pelas iniciais.

${ }^{19}$ Criado em abril de 1980, o END deveriaformular uma teoria geopolítica alternativa para movimentos sociais em luta contra o potencial extermínio da raça humana, e ser um movimento pacifista contra as armas de destruição em massa, a favor dos direitos humanos e da preservação ecológica. Em um processo liderado por Thompson, o grupo reuniu os principais líderes da CND, da

InternationalConfederation for Disarmamentand Peace e Pax Christi. O END diferenciava-se da CND por propor uma perspectiva mais internacionalista na análise da corrida armamentista e tentar coordenar a luta por um projeto alternativo para toda a Europa.

TrabalhoNecessário - www.uff.br/trabalhonecessario; Ano 14, No 23/2016. 


\section{Trabalhonecessário}

Issn: 1808 - 799X ano 14, número $23-2016$

temor mútuo de dissuasão poderia adiar uma confrontação total" . ${ }^{20}$ Thompson (1980a, p. 28) prossegue:

[A] dissuasão não é uma condição imóvel, fixa, é um estado de degradação. [...] Tem contido a exportação de violência contra o bloco oposto, mas, ao proceder assim, o poder repressivo do Estado [retorna] contra seu próprio criador. A violência reprimida tem sustentado e agido sobre a economia, a política, a ideologia e a cultura dos poderes antagônicos. Essa é a estrutura profunda da Guerra Fria.

Essa seria a lógica de justificação para a Guerra Fria e reprodução da corrida armamentista. Thompson (1982, p. 14-16) acredita que, no Ocidente, a culpa caberia à supremacia norte-americana e à falta de vontade de seus satélites europeus em rejeitar essa situação e a mentalidade aí contida. Isso porque, ainda segundo Thompson (1982, p. 14-15), a diplomacia norte-americana, respaldada em seu poderio militar, valia-se muito de seu poder de veto, o que impedia a existência de qualquer dissenso por parte dos países europeus. É esse, aliás, o contexto da proposta de um

"atlanticismo", sob a dominação dos Estados Unidos, não questionada na GrãBretanha, nem mesmo pelo supostamente oposicionista LabourParty.

Thompson demonstra como a Guerra Fria, independentemente de suas origens após a Segunda Guerra Mundial, parecia operar com uma dinâmica própria, uma lógica interna e um conjunto específico de argumentos, o que ocultava o forte interesse dos Estados envolvidos em sua continuidade.

Thompson (1982, p. 17) percebe que a reciprocidade das relações entre Estados Unidos e União Soviética era fundamental para essa lógica, um contexto em que uma forma de ação antagônica deveria ser sistematicamente igualada pelo antagonismo da resposta. Thompson (1982a, p. 332) não propunha uma identidade entre os blocos e sim

\footnotetext{
20 O termo "deterrence" tem uso corrente como "dissuasão", tanto na imprensa como na bibliografia em português. Expressa a política ou prática de armazenar armamentos nucleares, por parte de uma nação, para deter o ataque nuclear de outra; expressa também uma política de dissuasão e um projeto de limitação de armas nucleares a longo prazo. ("Each must be motivated, of its own inherent nature, by the desire to vanquish the other. Only the mutual fear of 'deterrence' can stave off a total confrontation").
}

TrabalhoNecessário - www.uff.br/trabalhonecessario; Ano 14, No 23/2016. 


\section{Trabalhonecessário}

Issn: 1808 - 799X ano 14, número $23-2016$

sua reciprocidade: a interação de ambos os blocos criava um problema nuclear internacional e uma situação de equivalência entre eles.Esse procedimento era determinante para que "os estabelecimentos militares e de segurança fossemautoreprodutivos"

Thompson (1982, p. 17-18) tem consciência de que a ideologia e a retórica que acompanhavam tal dinâmica eram inerentes ao processo e reproduziam-se a si mesmas, não só porque "os serviços militares e de segurança, e seus funcionários públicos, precisam da Guerra Fria (e) têm interesse direto em sua continuidade", mas também porque no interior dos países satélites cada movimento político ou militar deveria ser aprovado pelos governos de Washington ou Moscou, reforçando os mecanismos de dominação de ambos os centros.

Para desenvolver essa argumentação, e explicar os perigos do processo político e ideológico contido na Guerra Fria, Thompson introduz a metáfora da alteridade do Outro. Assim, a unidade necessária na frente doméstica pode ser explicada também em termos de preocupação e medo em relação aos "outros", à ameaça representada pelos "outros", consolidando, dessa forma, uma noção geral de "nós" em oposição a "eles". Ao perceber o "outro", "nós" nos distinguimos em relação a ele e, se o "outro" for construído como uma ameaça, o vínculo entre "nós" é reforçado.

Thompson (1982, p. 18) observa que esse "vínculo por exclusão" é intrínseco à socialização humana; é tão fundamental para a formação e a consciência de classe quanto para a construção de uma nação ou para sujeitar as pessoas a uma ideologia. Porém, esse processo cria uma ameaça e, no limite, aumenta o ódio pelos "outros".

Nas polêmicas da Guerra Fria essa cultura foi artificialmente invocada para assegurar os interesses dos respectivos blocos. Ambas as culturas e identidades nacionais (norte-americanas e soviéticas) entrelaçaram-se nas premissas ideológicas do conflito e as aprofundaram cada vez mais. Nesse sentido, esses conflitos contribuíram para introjetar o americanismo na população dos Estados Unidos (e na de outros países), a reforçar o mito do sonho americano (American dream), tornando-o uma atração em oposição à imagem de tirania do "outro" mundo, tirânico e sem liberdade. ${ }^{21}$

TrabalhoNecessário - www.uff.br/trabalhonecessario; Ano 14, No 23/2016. 
Issn: 1808 - 799X ano 14, número $23-2016$

Da mesma forma, a União Soviéticarepresentava-se a si mesma como a defensora do socialismo e o Partido como o titular da resistência ao imperialismo do Ocidente, não obstante a repressão sistemática a todo dissenso, em qualquer nível.

Entretanto, nenhum dos mundos era "o melhor dos mundos", ambos apresentavam novas definições sobre a condição do "outro" - e a necessidade da Guerra Fria novamente revelava-se e regenerava-se a si mesma.Thompson (1982, p. 23) reconhece que:

É uma condição permanente, auto-reprodutora, à qual ambos os adversários estão dedicados. Os estabelecimentos militares dos adversários encontram-se em uma relação recíproca de fomento mútuo: cada um estimula o crescimento do outro. Ambos os adversários precisam manter uma atitude ideológica de hostilidade, como meio de forçar a disciplina ou a coesão interna.

\section{Protestar para sobreviver}

Muitos militantes de esquerda na Inglaterra, ativos na campanha pelo desarmamento unilateral, chegaram à conclusão, nos anos de 1980, que havia um problema central na balança de poder criada pela Guerra Fria. Entre outros aspectos, a evidência demonstrava que nenhum dos blocos em antagonismo poderia "ganhar uma guerra". A luta definia-se em outro patamar, concentrando-se no questionamento e no enfraquecimento do processo e de suas premissas ideológicas. Para Thompson (1982, p. 25), a Europa era o ponto de tensão do sistema da Guerra Fria. Segundo ele:

Pela primeira vez, desde a Resistência do período da guerra, há um espírito circulando na Europa que carrega uma aspiração transcontinental. O Outro que nos ameaça está sendo redefinido - não como outras nações [ou] o outro bloco, mas como as forças que levam ambos os blocos à autodestruição; não "a Rússia" ou "os Estados 


\section{Trabalhonecessário}

Issn: 1808 - 799X ano 14, número $23-2016$

Unidos", mas suas instituições ideológicas, militares e de segurança, e suas oposições ritualísticas.

O programa desenvolvido pelo END na década de 1980 procurou organizar um novo radicalismo popular para enfrentar as motivações da Guerra Fria e seu status

${ }^{21}$ Cf. também Gramsci, A. (1972, p. 285-323), seu clássico ensaio "Americanismo e Fordismo", in Notas sobre Maquiavelo, sobre la política y sobre el Estado moderno.

quo. Seu projeto era o de conquistar a autonomia da Europa e garantir as condições de sua afirmação e manutenção. O movimento considerava o cenário do "teatro" europeu como um todo, ocupando uma posição única, pois oferecia pontosde acesso para o desenvolvimento de um processo de deslegitimação da Guerra Fria, a partir da própria arena de embate entre União Soviética e Estados Unidos.

Nessa época, a contribuição mais significativa de Thompson para esses debatesmas sobretudo contra a corrida armamentista, a ameaça nuclear e em nome da organização de grupos e movimentos pacifistas -talvez seja 0 ensaio (ProtestandSurvive), de 1980, em resposta à publicação do governo conservador inglês, ProtectandSurvive-documento que ensinava a população britânica a como se proteger no caso de um eventual ataque nuclear, e que fazia parte de um conjunto de propagandas nessa direção. ${ }^{21}$

No ensaio (ProtestandSurvive), Thompson antevê a Europa como o "teatro da paz" - não como o "teatro de guerra" -,resultante de pressão popular democrática. ${ }^{22}$ Entretanto, para isso acontecer, ainda seria necessária uma détente

${ }^{21}$ Cf. Thompson, E. P. (1980a, p. 33). A publicação de ProtestandSurvivefoi patrocinada pela Bertrand Russell Peace Foundation e pela CND. Cf. também Kaye, H. (1984, p. 218), onde ele traça um paralelo entre Thompson e Tom Paine no uso do formato de panfleto (pamphlet) para divulgar uma mensagem radical e atingir um público mais amplo. Cf. também entrevista de Thompson e Cory Coll, conduzida por Harry Kreisler, do InstituteofInternationalStudies, Berkeley, em 01 de agosto de 1983, sobre "armas nucleares, corrida armamentista e os movimentos pela paz", editada por Jon Stewart em California Living, Sept. 11, 1983. Ainda disponível pra consulta nos arquivos, cf. http://conversations.berkeley.edu

22 Thompson formulou suas ideias sobre a política como teatro, como representação do poder, esobre o contrateatro no protesto dos movimentos populares, em seus trabalhos dedicados às formas de rebelião nas sociedades pré-industriais e nos primeiros momentos do movimento operário. Cf. Thompson, E. P.

TrabalhoNecessário - www.uff.br/trabalhonecessario; Ano 14, Nº 23/2016. 


\section{Trabalhonecessário}

Issn: 1808 - 799X ano 14, número $23-2016$

internacional para assegurar um futuro independente do sistema de guerra. Ou seja, uma vez definida uma estratégia, as contradições do papel atribuído à Europa poderiam ser usadas contra os "guerreiros" em Washington e Moscou.

A construção dessa estratégia demandou tempo e dedicação de Thompson ao longo dos anos de 1980 e encorajou várias formas de resistência popular. Uma resistência necessária porque a política da Guerra Fria se estruturava de tal maneira que a ideia de extermínio da sociedade era perfeitamente coerente com a lógica do processo.

Nessa conjuntura, já em 1980, percebendo "a existência de uma dinâmica interna e uma lógica recíproca que requerem uma nova categoria de análise", Thompson (1982a, p. 4-5) elabora a categoriaexterminismo, inspirada em uma afirmação de Marx e, a seu ver, adequada para examinar a lógica e a dinâmica dessa nova realidade:

Se o moinho manual nos dá a sociedade com o suserano; o moinho a
vapor, a sociedade com o capitalista industrial, o que nos é dado por
esses satânicos moinhos em operação atualmente, triturando os meios
de extermínio humano? Já cheguei a esse ponto de reflexão mais de uma
vez, mas virei minha cabeça, desesperado, em outra direção. Agora,
quando examino o problema diretamente, concluo que a categoria de que
precisamos é a de exterminismo. (Grifo no original)

Apesar de essa proposição guardar um sentido determinista - mais tarde reconhecido e revisto por Thompson -, em termos teóricos, o aspecto mais controverso da interpretação de Thompson sobre o sistema da Guerra Fria é sua rejeição das noções de imperialismo e militarismo, associadas, segundo ele, a circunstâncias convencionais ou específicas, cada uma expressando diferentes níveis ou aspectos de uma crítica ao capitalismo:conceitos inadequados, portanto, para a análise da Guerra

(1974, p. 383-405), "Patrician Society, Plebeian Culture", in Journal of Social History, e (1998, p. 25-85), "Patrícios e Plebeus".A esfera teatral do exercício do poder político busca conformar os governados, manter seu consentimento, ativo ou passivo; perpetuar sua deferência, o respeito aos valores, símbolos e normas; fixar os limites do politicamente possível etolerável. Constitui parte fundamental da hegemonia, domínio não baseado diretamente na coerção material. Cf. Thompson, E. P. (1982a, p. 811), a seção "O 'Teatro do Apocalipse'", de seu ensaio "Notas sobre o Exterminismo", para se avaliar a relação entre a ideia de teatro e a lógica da estrutura da Guerra Fria.

TrabalhoNecessário - www.uff.br/trabalhonecessario; Ano 14, No 23/2016. 


\section{Trabalhonecessário}

Issn: 1808 - 799X ano 14, número $23-2016$

Fria. Segundo Thompson (1982a, p. 1-2), ambos traduzem um forte conteúdo ideológico e, em sua formulação, expressam a ideia de um sistema, racional de início, mas que eventualmente pode provocar sua própria implosão irracional. ${ }^{23}$

Thompson (1982a, p. 332-338) afirma que:

Necessitamos uma categoria nova [exterminismo] para definir esta época clara de história nuclear-confrontacional, e [...] isto não significa, mediante um gesto de varinha mágica, que seja necessário renunciar a todas as categorias anteriores ou que não funcionem mais todas as forças históricas anteriores. [...] Não se trata simplesmente de uma questão de força: é uma questão de legitimidade. Ali onde nenhuma forma de poder está legitimada pela responsabilidade civil e por um processo aberto como é devido, pode ocorrer que uma forma de poder dê lugar a outra. Cada uma destas formas de poder é tão legítima ou ilegítima quanto a outra.

O exterminismo da Guerra Fria se baseia na dinâmica do sistema de armamentos. Embora pareça um movimento racional, no qual os agentes participantes tomam decisões aparentemente racionais, como assinalamos, no âmago do processo desenvolve-se uma lógica perversa, um sistema de autogeração e um estado generalizado de inércia na direção da destruição total (Thompson, 1982a, p. 14-22).

Para além do imperialismo e do militarismo, os sistemas correspondentes a esses blocos podem ser vistos como complexos militares e industriais que a população civil é obrigada a sustentar (por meio de quotas de trabalho, investimentos, impostos, taxas, etc.). Para reproduzir o sistema, as elites governantes, segundo Thompson (1982a, p. 22),

passaram a precisar de uma situação permanente de guerra, de modo a legitimar sua dominação, seus privilégios e prioridades; para silenciar o dissenso; para exercer a disciplina social e desviar a atenção da evidente irracionalidade da operação. Eles se habituaram tanto a esse modo, que não conhecem outro modo de governar.

${ }^{23}$ Cf. Thompson, E. P. (1982a, p. 1-2). Ele comenta, mas sem maiores detalhes, que "a Primeira Guerra Mundial e o colapso do nazismo seriam exemplos de militarismo e imperialismo caminhando na direção de seus próprios fins". Para outros comentários sobre a comparação com o imperialismo, cf. (Thompson, 1982a, p. 14-24).

TrabalhoNecessário - www.uff.br/trabalhonecessario; Ano 14, N²3/2016. 
Issn: 1808 - 799X ano 14, número $23-2016$

Em sua lógica perversa, o processo político serve tão-somente para legitimar e justificar sua própria reprodução.Thompson lembra que sua geração testemunhou a guerra - inclusive o bombardeio nuclear sobre o Japão - e concordacom C. Wright Mills que "a causa imediata da Terceira Guerra Mundial é a sua preparação". ${ }^{24}$ Ambas as guerras anteriores foram previsíveis, assim como as guerras no Terceiro Mundo.

A "tecnologia do apocalipse" oferece sua própria previsibilidade: o extermínio da civilização no hemisfério norte. À sombra dessas colocações, Thompson insiste na formação de uma nova consciência. ${ }^{25}$ A questão da luta de classe permanece fundamental, mas o imperativo agora é o da salvação da própria humanidade, ou seja, com a perspectiva do exterminismo a causa se redefine.

A lógica exterminista, elaborada na perspectiva do confronto com o "outro", e as relações de poder que engendra devem ser sabotadas, combatidas e superadas, e a resistência popular é a que poderia apresentar uma alternativa humana viável.

Embora caracterizados por um profundo pessimismo e uma perspectiva apocalíptica, os ensaios de Thompson sobre exterminismo concluem com uma visão mais otimista e a formulação objetiva de propostas parainterromper e reverter a situação analisada - ainda que sempre priorizando o cenário europeu. Ao final de seu artigo, "Notes onexterminism, thelaststageofcivilization", Thompson (1982a, p. 30) conclama:

Dê-nos a vitória [nesse processo] e o mundo começará a se mover outra vez. Comece a quebrar esse campo de força e os 30 anos de impedimentos à mobilidade da política europeia [...] irão ceder. Nada irá acontecer natural ou facilmente [...]: mas se afastarmos esses blocos da rota de colisão, eles mesmos começarão a mudar. A polícia e os fabricantes e vendedores de armas irão começar a perder sua autoridade e os ideólogos perderão suas falas. Um novo espaço para a política irá se abrir.

\footnotetext{
${ }^{24}$ Cf. Wright Mills, C., The Causes of World War Three, New York: Simon \& Schuster, p. 47, 1958.

${ }^{25}$ Cf. Bahro, R. (1982a), "A new approach for the peace in Germany", in Thompson, E. P. (ed.) (1982a), p. 87-116.
}

TrabalhoNecessário - www.uff.br/trabalhonecessario; Ano 14, No 23/2016. 
Issn: 1808 - 799X ano 14, número $23-2016$

\section{Considerações finais}

Uma das principais motivações de Thompson em sua luta pelo fim da Guerra Fria, e pela causa humanista e pacifista, é o de reafirmar o imperativo da razão humana, como indicado na Introdução.Daí o protesto, o questionamento, as críticas contundentes contra oabsurdo da corrida armamentista, a importância de colocar em xeque sua necessidade e prioridade.

Do ponto de vista da lógica histórica, Thompson (1982a, p. 1) considera que o processo poderia ser submetido a uma estrutura racional de análise, mas o objeto, no momento da Guerra Fria, tornava-se ele próprio irracional. Adverte: sendo o presente historicamente determinado, está sujeito a uma análise racional, mas a permanente militarização e os avanços tecnológicos no campo das armas de destruição formam uma massa critica próxima do ponto de uma detonação irracional. Sua conclusão (1982, p. 24) era simples, a de que "essa lógica seria terminal, se não corrigida".

Para destacar o sentido de sua advertência,Thompson conclama na abertura de seu ensaio (1982a, p. 1), "Notas sobre o exterminismo(...)": "Camaradas, precisamos de uma análise válida, teórica e de classe,da atual crise bélica. Sim. Mas estruturar uma análise racional sucessiva pode, ao mesmo tempo, impor uma racionalidade de consequências ao objeto de análise. E se o objeto é irracional?".

Observa ainda (1982a, p. 1) que "usa 'racionalidade'nessas 'Notas' para designar a busca racional do interesse próprio, enquanto atribuido a uma nação, classe, elite política, etc. Em outra perspectiva, nenhuma dessas buscas precisa se apresentarcomo racional". E Thompson (1982a, p, 2) resume na primeira parte do artigo: "Não posso 


\section{Trabalhonecessário}

Issn: 1808 - 799X ano 14, número $23-2016$

oferecer mais do que notas, fragmentos de um raciocínio. Alguns fragmentos devem assumir a forma de questões, dirigidas ao imobilismo da esquerda marxista". ${ }^{26}$

Como os editores da editora New Left Books/Verso escreveram no Prefácio de Exterminism and Cold War - sobre a importância do projeto de Thompson e do livro com as contribuições de todos os autores que debateram com ele -, "uma interpretação histórica nessa escala implica uma recomendação política" (1982a, p. xii). Nesse sentido, Thompson procura, mais uma vez, realizar uma "chamada à razão" e convocar seus companheiros para uma nova campanha. Assim, quando Thompson considera o objeto de análise "irracional", trata-se, ao contrário, de formular uma nova teoria, referida a uma análise de classe para compreender o que está acontecendo e "agir em conseqüência". Trata-se, portanto, de reconstruir a razão, uma racionalidade que possa desenhar uma estratégia de luta e orientar novas ações contra a situação denunciada. Daí também o apelo de Thompson a seus "camaradas" (comrades, no original) contra o imobilismo ea apatia, como em 1960. ${ }^{27}$

A proposta objetiva de Thompson de uma luta-no-contexto agora representa um "imperativo humano e ecológico":

$[\mathrm{O}]$ internacionalismo deve ser conscientemente antiexterminista: deve se opor aos ditames ideológicos de ambos os blocos [e]; incorporar em seu pensamento, em suas trocas, [...] atitudes e expressões simbólicas os princípios da sobrevivência humana e ecológica. (Thompson, 1982a, p. 29)

Thompson (1982, p. 30) complementa e conclama:

Devemos correr o risco. Pois só podemos acabar com a Guerra Fria de duas maneiras: pela destruição da civilização europeia ou pela reunificação da cultura política europeia. A primeira irá acontecer se os grupos dominantes nos superpoderes rivais, percebendo que os argumentos estão mudando [...] e que seus estados-satélites estão se tornando mais independentes, terminarem por compensar essa perdade influência política e econômica com um aumento de medidas de

\footnotetext{
${ }^{26}$ Cf. Thompson, E. P. (1985a, p. 17).

${ }^{27}$ Cf. Thompson, E. P. et ali (ed) (1960), Out of Apathy.
}

TrabalhoNecessário - www.uff.br/trabalhonecessario; Ano 14, No 23/2016. 


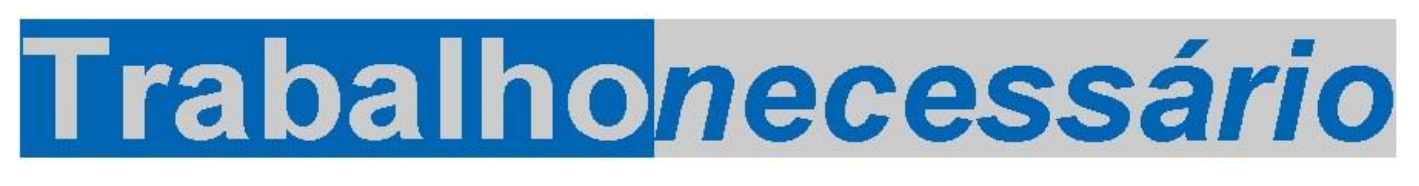

\author{
Issn: $1808-799 \mathrm{X}$ ano 14 , \\ número $23-2016$
}

militarização. Isto é [...] o que está acontecendo agora. O resultado será terminal. Mas podemosenxergar uma pequena abertura na direção da outra alternativa. E se acreditamos que essa alternativa seja possível, então devemos redefinir nossas prioridades. Não devemos investir mais nada em mísseis, mas sim o máximo em nossa capacidade de comunicação e diálogo.

De fato,Thompson não chegou a elaborar uma nova teoria, como pensou, e a categoria exterminismo não responde completamente à sua inquietação e às perguntas e necessidades formuladas. Massabemos que, como categoria,pode expressar o processo de transformação das relações sociais e deve ser compreendida em função da lógica histórica por ele definida.

Não obstante, as advertências de Thompson em seus textos sobre o exterminismo soam visionárias, tragicamente atuais. A ameaça de uma guerra ou de conflitos nucleares ainda existe - o que seria terminal, como ele adverte -, mas nos preocupamos, sobretudo, com a permanente capacidade de o capitalismo alimentar, reproduzir,intensificar diferentes formas de violência e de expressões fascistas em suas relações, como é próprio de sua lógica.

Após essa exposição, acreditamos que as hipóteses de Peter Linebaugh façam sentido.

Partindo de uma divisão formal do conjunto da obra de E. P. Thompson, percebemos melhor sua unidade, ao contrário. Se Linebaugh(1993, p. 101-102) propõe a morte violenta como um tema central e unificador entre seus escritos é justamente para tornar possível a aproximação entre várias questões presentes e fundamentais nos textos de Thompson: seja o enforcamento como uma pena capital, seja a guerra especialmente a nuclear. Somos colocados assim diante do problema de como enfrentar e lidar com a morte de um ou a morte de todos, ou seja, no limite, a violência como questão social e de classe. Dessa forma, Thompson propõe um dilema que precisa ser conhecido e enfrentado. Por esse motivo, a categoria exterminismo tornase uma ferramenta de conhecimento e de luta, em seu sentido provocativo, ao incomodar e mobilizar as pessoas e os movimentos sociais. Nesse sentido, o que interessa a 
Issn: 1808 - 799X ano 14, número $23-2016$

Thompson é, como dissemos, o agir em consequência, seu compromisso histórico por meio da ação política. Como lembra Linebaugh (1993, p. 102), Thompson era um soldado, não um pacifista: por isso, o pacifismo proposto por Thompson é uma estratégia de luta:

Como aprendemos da história, essa conjuntura de crise e oportunidade é o mais perigoso momento de todos. Os grupos dominantes, habituados a seus tradicionais hábitos e controles, sentem a terra se mexer embaixo deles. As pombas e os falcões formam facções. Ações podem ser impulsivas e precipitadas. Neutralismo, internacionalismo - impulsos democráticos no Leste, impulsos socialistas no Ocidente - tornam-se ameaças terríveis ao poder estabelecido, desafiando a própria razão de ser das elites exterministas. (Thompson, 1982a, p. 25).

Como Thompson (1982a, p. 30) proclamou, "o fim da política é agir, e agir com resultado". 29

\section{Referências}

BESS, Michael. Realism, Utopia, andtheMushroomCloud. Univ. of Chicago Press, 1993.

KALDOR, Mary (ed.). EuropeFromBelow. London: Verso, 1991.

KAYE, Harvey. The British MarxistHistorians. Cambridge: Polity Press, 1984.

LINEBAUGH, Peter. OneandAll, OneandAll: Edward Thompson (1924-1993).

LeftHistory, York University, vol.1, n. 2, p. 89-102, 1993.

THOMPSON, Edward P. et al. (ed.). Out ofApathy. London: Steven \& Sons/New Left Books 1960.

THOMPSON, E. P. The PovertyofTheoryandOtherEssays. London: The Merlin Press, 1978.

THOMPSON, E. P. WritingbyCandlelight. London: Merlin, 1980. 


\section{Trabalhonecessário}

Issn: 1808 - 799X ano 14, número $23-2016$

THOMPSON, E. P. ProtestandSurvive. London: CND \& Nottingham: Bertrand Russell Peace Foundation, 1980a.

THOMPSON, E. P. e SMITH, Dan (ed). Protest and Survive. Harmondsworth: Penguin, 1980b.

THOMPSON, E. P. A Miséria da Teoria. Rio de Janeiro: Zahar, 1981.

THOMPSON, E. P. BeyondtheCold War. London: Merlin \& END, 1982.

THOMPSON, E. P. (ed.). ExterminismandCold War. London: New Left Books/Verso,1982a.

THOMPSON, E. P. Zero Option. London: Merlin, 1982b.

THOMPSON, E. P. The Heavy Dancers. London: Merlin, 1985.

THOMPSON, E. P. The SykaosPapers. London: Bloomsbury, 1988.

THOMPSON, E. P. "Ends and Histories", in KALDOR, Mary (ed.). Europe From Below. London: Verso, p. 7-25, 1991.

THOMPSON, E. P. Costumes em Comum. S. Paulo: Companhia das Letras, 1998.

WILLIAMS, Raymond et al. (ed.). May Day Manifesto: 1968. Harmondsworth: Penguin, 1968.

29 No original, "The endofpoliticsistoact, andtoactwitheffect". 